\title{
An innovative online VFA monitoring system for the anerobic process, based on headspace gas chromatography
}

Boe, Kanokwan; Batstone, Damien J.; Angelidaki, Irini

Published in:

Biotechnology and Bioengineering

Link to article, DOI:

10.1002/bit.21131

Publication date:

2007

Link back to DTU Orbit

Citation (APA):

Boe, K., Batstone, D. J., \& Angelidaki, I. (2007). An innovative online VFA monitoring system for the anerobic process, based on headspace gas chromatography. Biotechnology and Bioengineering, 96(4), 712-721. https://doi.org/10.1002/bit.21131

\section{General rights}

Copyright and moral rights for the publications made accessible in the public portal are retained by the authors and/or other copyright owners and it is a condition of accessing publications that users recognise and abide by the legal requirements associated with these rights.

- Users may download and print one copy of any publication from the public portal for the purpose of private study or research.

- You may not further distribute the material or use it for any profit-making activity or commercial gain

- You may freely distribute the URL identifying the publication in the public portal 


\section{An innovative online VFA monitoring system for the anaerobic process, based on headspace gas chromatography}

Kanokwan Boe, Damien John Batstone and Irini Angelidaki*

Institute of Environment \& Resources DTU, Technical University of Denmark

Bygningstorvet, Building 115, DK-2800, Kongens Lyngby, Denmark

*Corresponding author. Phone: (+45) 45251429, Fax: (+45)45932850, E-mail: ria@er.dtu.dk 


\section{Abstract}

A new method for online measurement of volatile fatty acids (VFA) in anaerobic digesters has been developed based on headspace gas chromatography (HSGC). The method applies ex-situ VFA stripping with variable headspace volume and gas analysis by GC-FID. In each extraction, digester sample was acidified with $\mathrm{H}_{3} \mathrm{PO}_{4}$ and $\mathrm{NaHSO}_{4}$, then heated to strip the VFA into the gas phase. The gas was sampled in a low friction glass syringe before injected into the GC for measurement. The system has been tested for online monitoring of a lab-scale CSTR reactor treating manure for more than six months and has shown good agreement with off-line analysis. The system is capable of measuring individual VFA components. This is of advantage since specific VFA components such as propionic and butyric acid can give extra information about the process status. Another important advantage of this sensor is that there is no filtration, which makes possible application in high-solids environments. The system can thus be easily applied in a full-scale biogas reactor by connecting the system to the liquid circulation loop to obtain fresh sample from the reactor. Local calibration is needed but automatic calibration is also possible using standard addition method. Sampling duration is $25-40$ minutes, depending on the washing duration, and sensor response is 10 minutes. This is an appropriate for full-scale reactors, since dynamics within most biogas reactors are on the order of several hours.

Keywords: volatile fatty acids, online monitoring, anaerobic digestion, headspace analysis 


\section{Introduction}

The concentration of volatile fatty acids (VFA) is well known as an important indicator for monitoring of the anaerobic process. It gives fast and reliable information of process status compared to other common indicators such as $\mathrm{pH}$, alkalinity, gas production and gas composition (Hill and Holmberg, 1988; Hickey and Switzenbaum, 1991; Ahring et al., 1995; Björnsson et al., 2000; Mechichi and Sayadi, 2005). The total VFA concentration can be easily determined by titration, and several online titration systems have been proposed (Powell and Archer, 1989; Steyer et al., 2002). However, individual VFA can provide more information of the process status. Several studies have highlighted the importance of individual VFA as an early warning indicator for process failure (Hill and Holmberg, 1988; Hill and Bolte, 1989; Cobb and Hill, 1991; Ahring et al., 1995). These include the levels of iso-butyric and iso-valeric acid (Hill and Holmberg, 1988; Hill and Bolte, 1989; Cobb and Hill, 1991). Ahring et al. (1995) suggested the overall level of n-butyric and iso-butyric was the best indicator of process stress.

Methods proposed for offline individual VFA measurement involve sample filtration or centrifugation followed by either; direct injection into gas chromatograph (GC) (Angelidaki et al., 1990); solvent extraction followed by GC (Manni and Caron, 1995) or high-performance liquid chromatography (HPLC) (Albert and Martens, 1997); solid phase micro extraction (SPME) directly from the aqueous phase, followed by GC mass spectrometry (MS) (Pan et al., 1995; Yo, 1999); or static headspace chromatography (HSGC) (Cruwys et al., 2002). All of these offline methods are time consuming and most of them require extensive sample preparation before injection of the purified sample. With the advanced technology in high-rate anaerobic system and the increasing demand for process optimisation, rapid monitoring and control is necessary to deal with fast dynamic changes in high load anaerobic digesters. Detecting process changes, by individual VFA components prior to process failure, is an important key for successful process control and optimisation. 
Several systems have been reported for online measurement of individual VFA. Slater et al. (1990) used a GC with modified injection port for online analysis of VFA $\left(\mathrm{C}_{1}-\mathrm{C}_{4}\right)$ in a filtered liquid sample from a fluidised-bed reactor treating synthetic butyrate-based wastewater. Ryhiner et al. (1993) used GC for online analysis of acetic, propionic, butyric, valeric and iso-valeric in a UASB reactor treating whey powder solution. The sample was purified by membrane filtration, acidified by phosphoric acid and injected onto the GC column by an auto-sampler with a specially constructed flow-through vial. However, no performance data was shown for either of these systems. Zumbusch et al. (1994) used a HPLC for VFA analysis in a UASB reactor treating baker's yeast wastewater using an ultra-filtration module for sample purification. The results of acetic and propionic acid showed good agreement with the off-line GC. However, the crucial problem was membrane fouling requiring a high level of maintenance of the filtration system. Pind et al. (2003) used a GC for online analysis of six VFA components in a CSTR reactor treating manure. Sample purification employed a three step filtration; pre-filtration by a rotating filter inside the reactor, ultra filtration by a membrane cartridge, and a mini-filter for final purification. The sample was acidified with phosphoric acid before injected into GC by an auto-injector. The system showed good correlation with the offline measurement. However, membrane fouling was still the main problem and the membrane needed to be cleaned every 1518 hours to obtain sufficient flow.

It is clear that the efficiency of sample purification by membrane filtration decreases over time. The filter indeed suffers from fouling and requires extensive maintenance to obtain the required flows. In anaerobic digestion, the sampling system has to deal with complex, high-solid, or viscous samples, which makes membrane filtration even more susceptible to fouling. Especially for "difficult" substrates such as manure or solid waste, membrane fouling will be extensive. It is, therefore, preferable to avoid filtration for this kind of substrate. A method that can extract VFA without using any membrane filtration is through headspace extraction. 
There are several reports on applications of headspace gas chromatography (HSGC) for offline VFA analysis, including static HSGC (Cruwys et al., 2002) and dynamic HSGC (Ábalos et al., 2000). Static HSGC involves the equilibration of liquid or solid sample in a closed vial at high temperature to extract VFA into the gas phase and injection of the headspace gas with a gas tight syringe into the GC. Dynamic HSGC is done by continuous purging of the liquid or solid sample with inert gas through the headspace or sparging into the liquid. The volatiles are then trapped in an adsorbent and released under high temperature for GC measurement.

No references to online application of HSGC for VFA analysis have been found. All the online VFA systems presented currently are based on filtration, with consequent fouling problems. Gas extraction avoids this problem and thus has great potential to deal with hostile high solids environments. In this study we present an innovative VFA sensor for online monitoring of biogas reactors treating manure slurries. The method was modified from static HSGC to have variable headspace volume for gas extraction under atmospheric pressure.

\section{Materials and Methods}

In a closed system with liquid and gas in equilibrium, the partial pressure of a volatile component $\mathrm{P}_{\mathrm{i}}$ is a function of the vapour pressure of the pure component $\mathrm{P}_{\mathrm{i}}^{0}$, the mole fraction of the component in the solution $\mathrm{x}_{\mathrm{i}}$, and the activity coefficient of component in the solution $\gamma_{\mathrm{i}}$, as follows; (Seto, 1994)

$\mathrm{P}_{\mathrm{i}}=\mathrm{P}_{\mathrm{i}}^{0} \mathrm{x}_{\mathrm{i}} \gamma_{\mathrm{i}}$

$\gamma_{\mathrm{i}}$ is a the activity coefficient, caused by non-ideal behaviour of the solution, and tends towards 1 at infinite dilution. At relatively low concentrations, $\gamma_{i}$ can be assumed to be constant and Raoult's law can be simplified to Henry's law where the concentration of volatile in the gas phase $C_{G}$ is proportional to the concentration in the liquid phase $C_{L}$ as follow; (Kolb, 1976)

$\mathrm{C}_{\mathrm{L}} / \mathrm{C}_{\mathrm{G}}=\mathrm{K}_{\mathrm{H}}$

Where $\mathrm{K}_{\mathrm{H}}$ is partition coefficient, or dimensionless Henry's coefficient $\left(\mathrm{M}_{\mathrm{liq}} \mathrm{M}_{\mathrm{gas}}{ }^{-1}\right)$. 
A simple mass balance, comparing equilibrium $\left(\mathrm{C}_{\mathrm{L}}, \mathrm{C}_{\mathrm{G}}\right)$, and initial liquid concentration $\left(\mathrm{C}_{\mathrm{L}}{ }^{0}\right)$, assuming that neither the liquid volume $\left(\mathrm{V}_{\mathrm{L}}\right)$, nor gas volume $\left(\mathrm{V}_{\mathrm{G}}\right)$ change, with no initial gas phase concentration gives the following:

$\mathrm{C}_{\mathrm{L}}^{0} \mathrm{~V}_{\mathrm{L}}=\mathrm{C}_{\mathrm{L}} \mathrm{V}_{\mathrm{L}}+\mathrm{C}_{\mathrm{G}} \mathrm{V}_{\mathrm{G}}$

Substituting equation (2) into this gives:

$\mathrm{C}_{\mathrm{L}}^{0} \mathrm{~V}_{\mathrm{L}}=\mathrm{K}_{\mathrm{H}} \mathrm{C}_{\mathrm{G}} \mathrm{V}_{\mathrm{L}}+\mathrm{C}_{\mathrm{G}} \mathrm{V}_{\mathrm{G}}$

The sensor response, A, from headspace measurement is proportional to the gas phase concentration;

$$
A \propto C_{G}=\frac{C_{L}^{0}}{\left(K_{H}+\frac{V_{G}}{V_{L}}\right)}
$$

If the partition coefficient is very high, $\mathrm{K}_{\mathrm{H}} \gg \mathrm{V}_{\mathrm{G}} / \mathrm{V}_{\mathrm{L}}$, then $\mathrm{K}_{\mathrm{H}}+\mathrm{V}_{\mathrm{G}} / \mathrm{V}_{\mathrm{L}} \rightarrow \mathrm{K}_{\mathrm{H}}$, which is the case for VFA (Cruwys et al., 2002), equation (5) will be

$$
A \propto C_{G}=\frac{C_{L}^{0}}{K_{H}}
$$

This expression is the basis for the VFA analysis system.

\section{Implementation}

The concept applied is ex-situ VFA stripping, and headspace analysis by GC-FID (gas chromatography-flame ionization detection). The essential steps are as follows:

(a) $40 \mathrm{~mL}$ of liquid sampling from a recirculation loop to a sampling cell.

(b) Acidification with $4 \mathrm{~mL}$ of $34 \%$ phosphoric acid $\left(\mathrm{H}_{3} \mathrm{PO}_{4}\right)$ to obtain final $\mathrm{pH}<2$.

(c) Adding $2 \mathrm{~mL}$ of sodium hydrogen sulfate salt $\left(\mathrm{NaHSO}_{4}\right)$ to decrease solubility of VFA in the solution.

(d) Heating to $75^{\circ} \mathrm{C}$. 
(e) Gas sampling in a low friction glass syringe using a stepper motor for gas injection and 5-mL gas sampling loop for volume control.

(f) Gas injection and analysis in GC-FID

(g) Sample ejection, cleaning and flushing.

The response from the GC was compared to the concentration of VFA in liquid phase from offline analyses. This system used variable headspace volume to collect extracted gas and to maintain atmospheric pressure in the system during gas extraction, in contrast to the traditional static HSGC method, where the total gas volume is constant.

The schematic of the system used is shown in Figure 1. The sampling cell (S1) was made of a $100 \mathrm{~mL}$ glass beaker (Schott Duran, Wertheim/Main, Germany) with a hole custom made at the bottom for the effluent. The glass beaker was closed at the top by a silicone rubber stopper equipped with a sample tube, a gas tube, a temperature sensor $(\mathrm{T})$, a $\mathrm{pH}$ meter $(\mathrm{pH})$, a cartridge heater sealed in a stainless steel case $(\mathrm{H})$, and three small Teflon tubes (dia.2mm.) for acid $\left(34 \% \mathrm{H}_{3} \mathrm{PO}_{4}\right)$, salt $\left(62.2 \% \mathrm{NaHSO}_{2}\right)$ and washing agent $(33 \% \mathrm{NaOH})$. Sample removal at the base was through a normally closed pinch valve (V1), opened during sample exhaust and flushing. Six peristaltic pumps were used for sample circulation (P1), sample pumping (P2), water pumping (P3), acid addition (P4), salt addition (P5) and washing agent addition (P6).

The gas tube from the rubber stopper was connected to a gas valve (V2) which connected to the same manifold with the GC valve (V3), the compressed air valve (V4) and the friction-free gas syringe (S2). The gas syringe was $100 \mathrm{~mL}$ (Sanitex, Bassecourt, Switzerland), with outward movement limited by a Mclennan Servo Supplies 4 coil linear actuator (M1). S1 was continuously stirred by a magnetic stirrer (M2). All components, except for pumps, linear actuator and magnetic stirrer were heated inside a hotbox at $60{ }^{\circ} \mathrm{C}$ to prevent VFA condensation inside the gas tubes.

Gas injection to the GC was through a 6-way valve (S3) installed in the GC oven, with a sampling loop volume of $5 \mathrm{~mL}$ (L1). The automatic gas-sampling system operated in two modes; 
1) gas loading mode, in which the extracted gas was pressed out from the syringe (S2) by the linear actuator (M1) through the sampling loop (L1), and 2) injection, in which the contents of the loop were injected with $\mathrm{N}_{2}$ to the column.

VFA was analyzed by a Shimadzu GC-14A with FID detector. The GC column used was a fused-silica capillary column DB-FFAP, 30m x $0.53 \mathrm{~mm}$ I.D., with film thickness $1.5 \mu \mathrm{m}$. The injection port (splitless mode) and detector temperature were 150 and $200{ }^{\circ} \mathrm{C}$, respectively. The initial oven temperature was $70{ }^{\circ} \mathrm{C}$, increasing by $15{ }^{\circ} \mathrm{C} / \mathrm{min}$. to $170{ }^{\circ} \mathrm{C}$ and then $30{ }^{\circ} \mathrm{C} / \mathrm{min}$. to $190{ }^{\circ} \mathrm{C}$ after which the temperature was held for $3 \mathrm{~min} . \mathrm{N}_{2}$ was used for carrier gas.

Overall control was done by a programmable logic control (PLC) system (Versamax PLC, GE Fanuc Automation Europe S.A, Echternach, Luxembourg), with a PC interface. All calculations, including peak area calculation were managed within the PLC. The interface, and data logging on the PLC were using GE Cimplicity HMI 6.1 (HMI, GE Fanuc Automation Europe S.A).

\section{Sampling and Analysis Sequence}

The actuation sequence is shown in Table 1. The idle state of the sensor is with the sample cell (S1) filled with water to maintain the $\mathrm{pH}$ probe and prevent buildup of material. The sample and analysis sequence is as follows.

1. Idle Exhaust. Exhaust S1 by opening compressed air valve (V4), and exhaust valve (V1). Start sample circulation pump (P1).

2. Sample. Sample $10 \mathrm{~mL}$ by $\mathrm{P} 2$, with V1 open to flush the cell, followed by $40 \mathrm{~mL}$ with V1 closed for analysis.

3. Acid dose. Add 4mL 34\% $\mathrm{H}_{3} \mathrm{PO}_{4}$ via $\mathrm{P} 4$ for a final $\mathrm{pH}<2$. Open $\mathrm{V} 2$ and $\mathrm{V} 3$ to release $\mathrm{CO}_{2}$.

4. Headspace sampling. Close V3 and start heater $\mathrm{H}$. Add $2 \mathrm{~mL}$ of $62.2 \% \mathrm{NaHSO}_{4}$. Start linear actuator M1 in outward direction to allow the syringe to expand from headspace gas pressure. 
Heating and gas extraction runs over 6 minutes total. $60 \mathrm{~mL}-80 \mathrm{~mL}$ of extracted gas was acquired at atmospheric pressure during this step.

5. Headspace looping. Close V2 and open V3. Start M1 in inward direction to press gas through loop L1, with exhaust to atmosphere.

6. Injection. Switch valve S3 to nitrogen, through loop, to column, to inject contents of loop to GC for 1 minute, and start GC oven program. Switch back to pure nitrogen for GC column feed after 1-minute injection.

7. Cleaning. Flush with: (a) $80 \mathrm{~mL}$ water via P1, (b) $70 \mathrm{~mL}$ water via $\mathrm{P} 1$ plus $2 \mathrm{~mL} 33 \% \mathrm{NaOH}$ via P6, and (c) $80 \mathrm{~mL}$ water via P1, pressing out each flush as for 1. above using compressed air. Hold last flush until next sample as idle mode.

\section{Optimization and repeatability experiments}

Digested manure was used for optimization and repeatability tests. The manure was received from a biogas plant at Snertinge, Denmark and was stored at $4{ }^{\circ} \mathrm{C}$ before use. The VFA concentrations could still slowly change at this temperature, and therefore each test set was done in a short period (1-2 days). During each test, the sample bottle was stored in a cooling bath at 2 ${ }^{\circ} \mathrm{C}$ and replicates were taken from that sample bottle.

The optimisation of the method was done by sampling the digester sample with varying added acid volume, salt solution volume, equilibration temperature and equilibration time.

The repeatability test was done by resampling 10-15 times from the same sample. Synthetic VFA solution was also added to a digester sample to evaluate the effect of VFA concentration on the reproducibility.

The influence of bicarbonate alkalinity was assessed in a synthetic VFA solution by adding $\mathrm{NaHCO}_{3}$ as bicarbonate alkalinity to a final alkalinity level of 1 to $7 \mathrm{~g} \mathrm{~L}^{-1}$ as $\mathrm{CaCO}_{3}$. 


\section{Online experiments and analysis}

A 9-L CSTR reactor with 7.2 L working volume, treating cow manure was used for the online experiment. The reactor was operated at $55^{\circ} \mathrm{C}$ with a hydraulic retention time (HRT) of 15 days. Samples from the reactor were collected daily for offline VFA analysis. Offline VFA analysis was done by adding $50 \mu \mathrm{L}$ of $17 \% \mathrm{H}_{3} \mathrm{PO}_{4}$ to $1 \mathrm{~mL}$ sample in a $2 \mathrm{~mL}$ Eppendorf tube and centrifugation at $12000 \mathrm{rpm}$ for $10 \mathrm{~min}$. The supernatant was transferred into a vial for analysis in a gas chromatograph (GC) HP 5890 Series II equipped with flame ionization detector and a FFAP fused-silica capillary column, $30 \mathrm{~m}$ x $0.53 \mathrm{~mm}$ I.D. with film thickness $1.5 \mu \mathrm{m}$, using nitrogen as a carrier gas. The oven temperature was initially set at $70{ }^{\circ} \mathrm{C}$ with temperature increase at 10 degrees/min. to $190{ }^{\circ} \mathrm{C}$ and final hold of $3 \mathrm{~min}$. The injection port and detector temperature were 150 and $200{ }^{\circ} \mathrm{C}$, respectively. Reactor gas production was measured by an automated displacement gas metering system with a $100 \mathrm{~mL}$ displacement volume (Angelidaki et al., 1992). The water was adjusted to $\mathrm{pH} 3$ by $\mathrm{HCl}$ and with added $\mathrm{NaCl}$ to prevent $\mathrm{CO}_{2}$ dissolution.

\section{Results}

Overall results indicated that the system was effective and reliable after optimisation of materials, geometry, and operating conditions. Generally harsher operating environments (higher temperature, and low $\mathrm{pH}$ ) resulted in higher extractions, but required more durable materials. Geometry was critical to mitigate foaming as discussed further below. After optimisation, the system gave repeatable results, and was robust, operating over six months of reliability testing, followed by six months of on-line comparison. All samples were cow manure. 


\section{Optimization}

The liquid working volume was $40 \mathrm{~mL}$ in an $80 \mathrm{~mL}$ glass beaker reaction cell. The $40 \mathrm{~mL}$ headspace was enough to contain foam created during acid addition. The optimum acid addition was $1 \mathrm{~mL} \mathrm{34 \%} \mathrm{H}_{3} \mathrm{PO}_{4}$ per $10 \mathrm{~mL}$ sample, which gave a final $\mathrm{pH}$ below 2. More acid volume decreased sensor response due to dilution of VFA sample. (see Figure 2a) A higher acid concentration was not suitable due to a high viscosity of acid, which made it difficult to pump. The optimal temperature was $75{ }^{\circ} \mathrm{C}$ (see Figure $2 \mathrm{~b}$ ). Increasing temperature could increase sensor response. However, this factor was limited by material heat resistance. The optimal salt addition was $0.5 \mathrm{~mL}$ of saturated $\mathrm{NaHSO}_{4}$ per $10 \mathrm{~mL}$ sample which could increase the sensor response up to $200 \%$ of control without salt for acetic acid (see Figure 2c, d). The optimal equilibrium time was 6 min. Increasing equilibrium time decreased response due to condensation of water vapour in the gas tubes (see Figure 2e).

Material and geometry of the reaction cell had a significant impact on mixing and, thus, the sensor sensitivity. A previously designed reaction cell was made of acrylic plastic with conical shape and total volume of $150 \mathrm{~mL}$. It was found that the material deteriorated after testing for 8 months, and glass was the most suitable material for the reaction cell. For the gas tubes, glass, stainless steel and Teflon were all suitable. The reaction cell with a cone shape had less efficient mixing and poorer foam mitigation compared to a cylindrical shape with large sample volume. High $\mathrm{V}_{\mathrm{G}} / \mathrm{V}_{\mathrm{L}}$ ratio in the conical reaction cell resulted in a large dead volume of gas. Since the system is mass limited, the system showed high response when the sampling cell had low $\mathrm{V}_{\mathrm{G}} / \mathrm{V}_{\mathrm{L}}$ ratio.

Increasing the $\mathrm{GC}$ gas sampling loop volume from $1 \mathrm{~mL}$ to $5 \mathrm{~mL}$ improved the response almost 5 times. Pressurising the sampling loop by closing the syringe could also increase the response, but the results fluctuated due to skipped steps (in the motor), and hence, fluctuations in pressure. Therefore, injection under atmospheric conditions had the more stable response. 
Increasing bicarbonate alkalinity from $2 \mathrm{~g} \mathrm{~L}^{-1}$ to $4 \mathrm{~g} \mathrm{~L}^{-1}$ gave slightly higher sensor responses (approx. 20\%, see Figure 3). Increasing alkalinity further from $4 \mathrm{~g} \mathrm{~L}^{-1}$ upwards produced little impact. In manure digesters, alkalinity is usually stable above $3 \mathrm{~g} \mathrm{~L}^{-1}$ and thus will not cause errors.

\section{Measurement}

The sensor responses against GC offline analysis are shown in Figure 4 for samples taken from the CSTR. These correlations were used for sensor calibration. The lower detection limit of the system was $5,0.7,0.3,0.3,0.1,0.1 \mathrm{mM}$ for acetic, propionic, iso-butyric, butyric, iso-valeric and valeric acid, respectively. This was determined by the level of background response obtained from a blank sample (carryover). However, for normal anaerobic digestion system of agricultural waste or solid waste, the VFA levels are above this level.

\section{Repeatability test}

Repeatability test indicated consistent response to different levels, and minimal autocorrelation. That is, there was minimal drift, or other temporal relationships. For each concentration the variations in sensor response were compared in term of percentage of standard deviation to the average value of sensor response, $\%[$ stdev./ave.], and shown in the Table $2 \mathrm{~A}$. This shows that the variation of sensor response was high at low VFA concentration. However, when VFA concentration in the sample increased, the variation decreased and was considered to be acceptable compared to the variation from the determination of VFA by manually liquid preparation shown in Table $2 \mathrm{~B}$. In Table 2B, the determination of VFA by manual measurement (manual sampling and sample preparation) showed a variation of $8-13 \%$, which was in the same range as from the VFA online sensor at total VFA higher than $10 \mathrm{mM}$ (see Table 2A). 


\section{Online application}

The online application was to follow dynamic changes of VFA, and demonstrate long-term reliability. Extraction was using optimum conditions as stated above. The online VFA results were compared to the liquid VFA concentration measured by GC-FID. Results are shown in Figure 5. The increase of VFA concentration in the reactor was the result of several changes in the feed. From day 0 the reactor was started with high organic load and all VFA increased. At day 20 the feed was stopped and VFA decreased. Load was decreased with a HRT 72 days until day 60 after which feed flow was doubled to a HRT of 36 days. In response to this, only a small change in acetic acid was observed. At day 77, $85 \mathrm{~g}$ of rapeseed oil was added as a pulse and at day 90 the feed flow was doubled again to HRT 18 days. At this point the acetic acid increased more and propionic, iso-butyric and iso-valeric started to appear. However, the VFA decreased again, probably due to microbial adaptation. After day 110 the reactor was pulsed with different substrates, including rapeseed oil pulse of $157 \mathrm{~g}$ at day 111; glucose pulse of 25, 50, 50 and 100 $\mathrm{g}$ at day $125,137,161$ and 167 , respectively; and gelatine pulse of $25 \mathrm{~g}$ at day 142 . These pulses increased the concentration of mainly acetic and propionic acid and sometimes also other VFA depending on the organic load of the pulse. From day 185 to day 196, the reactor was fed with extra organic load by adding glucose, rapeseed oil and fibres in the feed. This caused an increase in VFA. Recovery following removal of the additional load was rapid although propionate was shown to be persistent in the reactor. The trends for all online individual VFA analysis followed offline analysis well, with no non-linearity, and minimal noise. Fluctuation of the sensor response was mainly due to humidity. When the heating box was cold, humidity in the system would condense in the gas tubes which decreased the sensor response. However, when the temperature was kept higher than $60{ }^{\circ} \mathrm{C}$ there was no condensation in the gas system.

Biofilm growth was found on the inner side of the sample tube after several months of operation. This decreased sample volume pumped into the sampling cell and also caused tube 
clogging by straw and particles that accumulated on this biofilm. Maintenance by cleaning the sampling tube every 2-3 months was found to be enough to prevent this problem.

\section{Discussions}

\section{Optimization}

A large sample volume provides a large liquid inventory of VFA to be extracted. However, it also leads to less efficient mixing. In the manure samples, $\mathrm{CO}_{2}$ bubbles caused foaming during acid addition which limited gas transfer, especially with large sample volumes. This can be mitigated with mixing, which breaks the foam down. In static HSGC applications, equilibrium times were up to $30 \mathrm{~min}$. (Stanbridge et al., 1993; Cruwys et al., 2002). In this system, extraction was much faster, because mixing by the magnetic stirrer helped to accelerate the equilibrium. The shape of the equilibrium cell can also influence mixing efficiency.

The volume of acid added should also be kept to a minimum to minimise dilution and maximise the GC response. Volatile inorganic acids such as hydrochloric acid are not recommended because the $\mathrm{HCl}$ vapour destroys the $\mathrm{GC}$ column and creates unpleasant odours, and perhaps health and safety problems. It is preferable to use non-volatile inorganic acid for this system to avoid smell problem, such as $\mathrm{H}_{3} \mathrm{PO}_{4}$ with Henry's constant of $1.4 \times 10^{11} \mathrm{M} \mathrm{atm}^{-1}$ or $\mathrm{H}_{2} \mathrm{SO}_{4}$ with Henry's constant of of $1.3 \times 10^{8} \mathrm{M} \mathrm{atm}^{-1}$. $\mathrm{HCl}$ and VFA have a Henry's constant in the range of $10^{4} \mathrm{M} \mathrm{atm}^{-1}$.

The partition coefficient, $\mathrm{K}_{\mathrm{H}}$ is highly dependent on the temperature. The value decreased when increasing temperature and when increasing ionic strength of the solution by adding salts. However, more water vaporizes under high temperature, resulting in high pressure in the system. For safety reason, the maximum temperature reported in literature for VFA extraction in static headspace measurement was up to $90{ }^{\circ} \mathrm{C}$ (Stanbridge et al., 1993). In this VFA system, the 
maximum temperature applied was rather limited by material heat resistance of the cell, and small volumes of salt were preferred to minimize sample dilution.

According to Bohnenstengel et al. (1993), interactions between volatile compounds themselves or between volatile compounds and sample matrix could influence the headspace composition, where the highly volatile compound depresses gas phase concentration of the less volatile compound. Similarly for this system, bicarbonate alkalinity in manure changes to $\mathrm{CO}_{2}$ gas during acid addition and can also affect the volatilisation of VFA. Therefore, the acid was added under open headspace to remove $\mathrm{CO}_{2}$ before VFA extraction to minimise the effect of $\mathrm{CO}_{2}$ partial pressure on the VFA extraction and to increase VFA partial pressure in the extracted gas.

The traditional static HSGC has constant headspace volume, and most of the commercial applications pressurize the vials with carrier gas before injecting into the GC (Kolb, 1999; Markelov and Bershevits, 2001). This results in low sensitivity, and the pressurized method makes it difficult to control the reproducibility of the analysis. In our method, VFA was extracted into a variable headspace volume (constant pressure), which reduces the variability, and total amount of VFA. The equilibrium pressure was also close to $1 \mathrm{~atm}$ so the effect of pressure on equilibrium would be eliminated. Moreover, the extracted gas itself acts as a carrier gas avoiding dilution by the carrier of the gas sample.

\section{Calibration}

Before effective on-line application to a new process, a local calibration is needed. In static HSGC application, external and internal standards have been used for offline VFA determination (Chen et al., 1994; Cruwys et al., 2002). An external standard was used by running a standard through the equipment, and comparing the peak area. This can only be applied when the sample has a similar matrix as the standard solution (Chen et al., 1994; Cruwys et al., 2002). An internal standard was used by adding a known concentration of internal standard to the sample. The ratio 
of response from internal standard to the response of each VFA was used to calculate the concentration of VFA. To apply this method directly, the chosen internal standard must have similar properties and be affected by the sample matrix similarly to the VFA, such as 2ethylbutyric acid (Cruwys et al., 2002).

When matrix effect had strong influence, the standard addition method was recommended, where the VFA standard was added to the sample and the extra response will be accounted for the known amount of added VFA (Stanbridge et al., 1993; Yo, 1999). In this study, the calibration was done using principle of the standard addition method. The sensor responses were directly compared to the offline VFA results and the correlations between liquid VFA concentrations and the sensor responses were used as calibration factor for the rest of the measurements. The online sensor was also re-calibrated after maintenance.

The methods of external standard, internal standard and standard addition are possible to manage automatically depending on the sample type. If the sample has similar matrix as standard VFA solution, the external standard method can be applied. For complex sample such as manure or solid waste, the method of standard addition is more suitable to avoid the effect of sample matrix.

\section{Improving the system}

The sensitivity of the system could be improved by increasing sample volume and optimised mixing to accelerate equilibrium and to remove foam for better gas transfer. Additionally, the sensor response can be increased by increasing gas sampling loop volume. Since high temperature in the gas tubes is needed in order to keep all VFA in the vapour form, an automatic temperature control will be necessary and the air used for flushing the system should run through a preheating coil in order to avoid cooling of the system during flushing. Choosing stronger material and equipment would greatly improve robustness of the system. 


\section{Fields of application}

The sensor response from acetic acid was quite low compared to the responses from other VFA at the same liquid concentration. In normal samples where acetic acid concentration is much higher than other VFA, sensor responses from all VFA are in the same range. This fits well with real application requirements to anaerobic digesters since acetic acid is normally presented in high amount, while other VFA are in low level and will increase during process instability.

An important advantage of this sensor is that no filtration unit is needed. As a consequence, this system can easily handle a wide range of samples from liquid, slurry, particulate substrate, or solid waste. Addition of acid before gas extraction would also help homogenise the sample in case of viscous or solid sample. However, the type of sample applied to the system is limited by pumping capability and the tube size but this can be modified according to the sample properties.

Another advantage is that the system takes the reactor sample from the liquid circulation loop, which makes it able to work with any kinds of reactor configurations and one sensor can be connected to several reactors by using the liquid circulation loop to transfer the fresh sample to the system.

Finally, the system has a simple method concept which should make it applicable to many anaerobic digestion processes. In the present sensor design, all parts, except for GC machine, can be indeed assembled by a local workshop. The sampling cell can be automatically cleaned by caustic solution during washing cycle. The gas tubes could be operated for many months before any cleaning requirement. No equipment part in the system is consumable except for chemicals and gases for the GC. The GC maintenance is also minimised because gas sample are much cleaner than liquid sample. The sample volume of $40 \mathrm{~mL}$ can easily be applied in a full-scale reactor. The total sampling time ranges from 25-40 min. depending on the washing duration, which is not critical for most of the full-scale biogas reactors since the VFA dynamics is in the range of several hours. 
The ability to closely monitor individual VFA will lead to great improvement in anaerobic digestion technology. Many further works can be done by the use of the online VFA sensor. The individual VFA data can be used for improving anaerobic digestion model for better understanding of the process behavior and dynamics. Single or several individual VFA can be used as reliable process indicator. These process indicators are useful for problem-solving and can be coupled with different control strategies to find optimal control for process start-up and optimization.

\section{Conclusions}

An innovative online VFA monitoring system based on HSGC has been developed. The system is capable to measure individual VFA components and has lower detection limit of 5, 0.7, 0.3, $0.3,0.1,0.1 \mathrm{mM}$ for acetic, propionic, iso-butyric, butyric, iso-valeric and valeric acid, respectively. The upper limit can be up to $150 \mathrm{mM}$ for acetic acid, $40 \mathrm{mM}$ for propionic acid, 20 $\mathrm{mM}$ for butyric and valeric acid, and $10 \mathrm{mM}$ for iso-butyric and iso-valeric acid. The advantage of this system is that it has no filtration part which makes it easy to maintain and suitable for thick sample such as manure slurries and solid waste. The system has been optimized and tested for reproducibility with manure sample. The results from online application with a lab-scale CSTR reactor treating manure has shown good agreement with the offline VFA analysis. The system can thus be easily applied in a full-scale biogas reactor by connecting the sample pump to the liquid circulation loop to obtain fresh sample from the reactor.

\section{Acknowledgements}

This work was supported by the Ph.D. scholarship from the Institute of Environment and Resources, Technical University of Denmark. 


\section{References}

Ábalos, M., Bayona, J. M. and Pawliszyn, J. (2000) Development of a headspace solid-phase microextraction procedure for the determination of free volatile fatty acids in waste waters. Journal of Chromatography A, 873, 107-115.

Ahring, B. K., Sandberg, M. and Angelidaki, I. (1995) Volatile fatty acids as indicators of process imbalance in anaerobic digestors. Applied Microbiology and Biotechnology, 43, 559-565.

Albert D.B., Martens C.S. (1997) Determination of low-molecular-weight organic acid concentrations in seawater and pore-water samples via HPLC. Marine Chemistry, 56, 27-37.

Angelidaki, I., Ellegaard, L. and Ahring, B. K. (1992) Compact automated displacement gas metering system for measurement of low gas rates from laboratory fermentors. Biotechnology and Bioengineering, 39, 351-353.

Angelidaki, I., Petersen, S. P. and Ahring, B. K. (1990) Effects of lipids on thermophilic anaerobic digestion and reduction of lipid inhibition upon addition of bentonite. Applied Microbiology and Biotechnology, 33, 469-472.

Björnsson, L., Murto, M. and Mattiasson, B. (2000) Evaluation of parameters for monitoring an anaerobic co-digestion process. Applied Microbiology and Biotechnology, 54, 844-849.

Bohnenstengel, F., Soltani, N. and Baltes, W. (1993) Headspace analysis with large sample volumes: Influence of sampling device volume, analyte concentration and sample matrix. Journal of Chromatography A, 655, 249-255.

Chen, A., Liao, P. H. and Lo, K. V. (1994) Headspace analysis of malodorous compounds from swine wastewater under anaerobic treatmetn. Bioresource Technology, 49, 83-87.

Cobb, S. A. and Hill, D. T. (1991) Volatile fatty acid relationships in attached growth anaerobic fermenters. Transactions of the ASAE, 34, 2564-2572.

Cruwys, J. A., Dinsdale, R. M., Hawkes, F. R. and Hawkes, D. L. (2002) Development of a static headspace gas chromatographic procedure for the routine analysis of volatile fatty acids in wastewaters. Journal of Chromatography A, 945, 195-209. 
Hickey, R. F. and Switzenbaum, M. S. (1991) Thermodynamics of Volatile Fatty-Acid Accumulation in Anaerobic Digesters Subject to Increases in Hydraulic and Organic Loading. Research Journal of the Water Pollution Control Federation, 63, 141-144.

Hill, D. T. and Bolte, J. P. (1989) Digester stress as related to iso-butyric and iso-valeric acids. Biological Wastes, 8, 33-37.

Hill, D. T. and Holmberg, R. D. (1988) Long chain volatile fatty acid relationships in anaerobic digestion of swine waste. Biological Wastes, 23, 195-214.

Kolb, B. (1976) Application of an automated head-space procedure for trace analysis by gas chromatography. Journal of Chromatography, 122, 553-568.

Kolb, B. (1999) Headspace sampling with capillary columns. Journal of Chromatography A, 842, 163205.

Manni, G. and Caron, F. (1995) Calibration and determination of volatile fatty acids in waste leachates by gas chromatography. Journal of Chromatography A, 690, 237-242.

Markelov, M. and Bershevits, O. A. (2001) Methodologies of quantitative headspace analysis using vapor phase sweeping. Analytica Chimica Acta, 432, 213-227.

Mechichi, T. and Sayadi, S. (2005) Evaluating process imbalance of anaerobic digestion of olive mill wastewaters. Process Biochemistry, 40, 139-145.

Pan, L., Adams, M. and Pawliszyn, J. (1995) Determination of fatty acids using solid-phase microextraction. Analytical Chemistry, 67, 4396-4403.

Pind, P. F., Angelidaki, I. and Ahring, B. K. (2003) A new VFA sensor technique for anaerobic reactor systems. Biotechnology and Bioengineering, 82, 54-61.

Powell, G. E. and Archer, D. (1989) On-line titration method for monitoring buffer capacity and total volatile fatty acid levels in anaerobic digesters. Biotechnology and Bioengineering, 33, 570-577.

Ryhiner, G. B., Heinzle, E. and Dunn, I. J. (1993) Modeling and simulation of anaerobic wastewater treatment and its application to control design: Case Whey. Biotechnology Progress, 9, 332-343. 
Seto, Y. (1994) Determination of valitile substances in biological samples by headspace gas chromatography. Journal of Chromatography A, 674, 25-62.

Slater, W. R., Merigh, M., Ricker, N. L., Labib, F., Ferguson, J. F. and Benjamin, M. M. (1990) A microcomputer-based instrumentation system for anaerobic wastewater treatment processes. Water Research, 24, 121-123.

Stanbridge, E. M., Mills, G. A. and Walker, V. (1993) Automated headspace gas chromatographic analysis of faecal short-chain fatty acids. Journal of Chromatography B, 621, 7-13.

Steyer, J.-P., Bouvier, J. C., Conte, T., Gras, P. and Sousbie, P. (2002) Evaluation of a four year experience with a fully instrumented anaerobic digestion process. Water Science and Technology, 45, 495-502.

Yo, S. P. (1999) Analysis of volatile fatty acids in wastewater collected from a pig farm by a solid pahse microextraction method. Chemosphere, 38, 823-834.

Zumbusch, P. V., Meyer-Jens, T., Brunner, G. and Märkl, H. (1994) On-line monitoring of organic substances with high-pressure liquid chromatography (HPLC) during the anaerobic fermentation of waste-water. Applied Microbiology and Biotechnology, 42, 140-146. 
Biotechnology and Bioengineering, 96(4):712-721.

Table 1. Output actuation matrix for operation of the sensor.

\begin{tabular}{|c|c|c|c|c|c|c|c|c|c|c|c|c|c|c|c|}
\hline Sampling procedure & $\begin{array}{l}\leq \\
1 \\
\text { 윰 } \\
\frac{\Phi}{3}\end{array}$ & 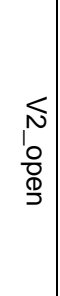 & $\begin{array}{l}\hat{\omega} \\
\frac{0}{0} \\
\frac{\mathbb{D}}{J}\end{array}$ & $\begin{array}{l}\lesssim \\
1 \\
\frac{0}{0} \\
\frac{\mathbb{D}}{2}\end{array}$ & I $^{\text {음 }}$ & $\stackrel{\square}{\underset{1}{0}}$ & $\begin{array}{l}\text { U. } \\
\mathrm{I}^{\circ}\end{array}$ & 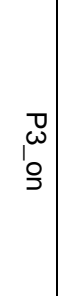 & $\begin{array}{l}0 \\
\stackrel{+}{1} \\
\\
\end{array}$ & $\begin{array}{l}\text { co } \\
\text { I }\end{array}$ & $\begin{array}{l}\text { ○ } \\
\text { ऽ } \\
\text { ᄋ }\end{array}$ & 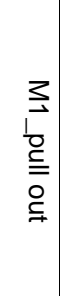 & 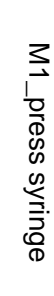 & 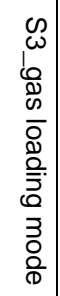 & 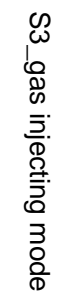 \\
\hline Empty sampling cell and flush with air & $\mathrm{X}$ & $\mathrm{X}$ & $\mathrm{X}$ & $\mathrm{X}$ & & $\mathrm{X}$ & & & & & & & $\mathrm{X}$ & $\mathrm{X}$ & \\
\hline Rinse sampling cell with sample solution & $\mathrm{X}$ & $\mathrm{X}$ & $\mathrm{X}$ & & & $\mathrm{X}$ & $\mathrm{X}$ & & & & & & & $\mathrm{X}$ & \\
\hline Pump sample into sampling cell & & $\mathrm{x}$ & $\mathrm{X}$ & & & $\mathrm{X}$ & $\mathrm{X}$ & & & & & & & $\mathrm{x}$ & \\
\hline Add acid to the sample & & $\mathrm{X}$ & $\mathrm{X}$ & & & & & & $\mathrm{X}$ & & & & & $\mathrm{X}$ & \\
\hline Add salt and start heating (Equilibration) & & $\mathrm{X}$ & & & $\mathrm{X}$ & & & & & $\mathrm{X}$ & & $\mathrm{X}$ & & $\mathrm{X}$ & \\
\hline Load gas to the sampling loop & & & $\mathrm{X}$ & & & & & & & & & & $\mathrm{X}$ & $\mathrm{X}$ & \\
\hline Inject gas from the sampling loop to GC & & & & & & & & & & & & & & & $\mathrm{X}$ \\
\hline Empty sampling cell and flush with air & $\mathrm{X}$ & $\mathrm{X}$ & $\mathrm{X}$ & $\mathrm{X}$ & & & & & & & & $\mathrm{X}$ & & $\mathrm{X}$ & \\
\hline Rinse sampling cell with water (1) & & $\mathrm{X}$ & $\mathrm{X}$ & & & & & $\mathrm{X}$ & & & & & $\mathrm{X}$ & $\mathrm{X}$ & \\
\hline Empty sampling cell and flush with air & $\mathrm{X}$ & $\mathrm{X}$ & $\mathrm{X}$ & $\mathrm{X}$ & & & & & & & & $\mathrm{X}$ & & $\mathrm{X}$ & \\
\hline Rinse sampling cell with water and $\mathrm{NaOH}(2)$ & & $\mathrm{X}$ & $\mathrm{X}$ & & & & & $\mathrm{X}$ & & & $\mathrm{X}$ & & $\mathrm{X}$ & $\mathrm{X}$ & \\
\hline Empty sampling cell and flush with air & $\mathrm{X}$ & $\mathrm{x}$ & $\mathrm{x}$ & $\mathrm{x}$ & & & & & & & & $x$ & & $\mathrm{X}$ & \\
\hline Rinse sampling cell with water (3) & & $x$ & $\mathrm{X}$ & & & & & $x$ & & & & & $\mathrm{x}$ & $\mathrm{X}$ & \\
\hline Empty sampling cell and flush with air & $\mathrm{X}$ & $\mathrm{X}$ & $\mathrm{X}$ & $\mathrm{X}$ & & & & & & & & $\mathrm{X}$ & & $\mathrm{X}$ & \\
\hline Rinse sampling cell with water (4) & & $\mathrm{x}$ & $\mathrm{X}$ & & & & & $\mathrm{X}$ & & & & & $\mathrm{X}$ & $\mathrm{X}$ & \\
\hline Flush sampling loop with air & & & $\mathrm{X}$ & $\mathrm{X}$ & & & & & & & & $\mathrm{X}$ & & $\mathrm{x}$ & \\
\hline
\end{tabular}


Biotechnology and Bioengineering, 96(4):712-721.

Table 2. Measurement variations in term of relative percent standard error (stdev/mean); A, from online sensor responses during repeatability test; B, from offline measurements manually prepared for 10 replicates

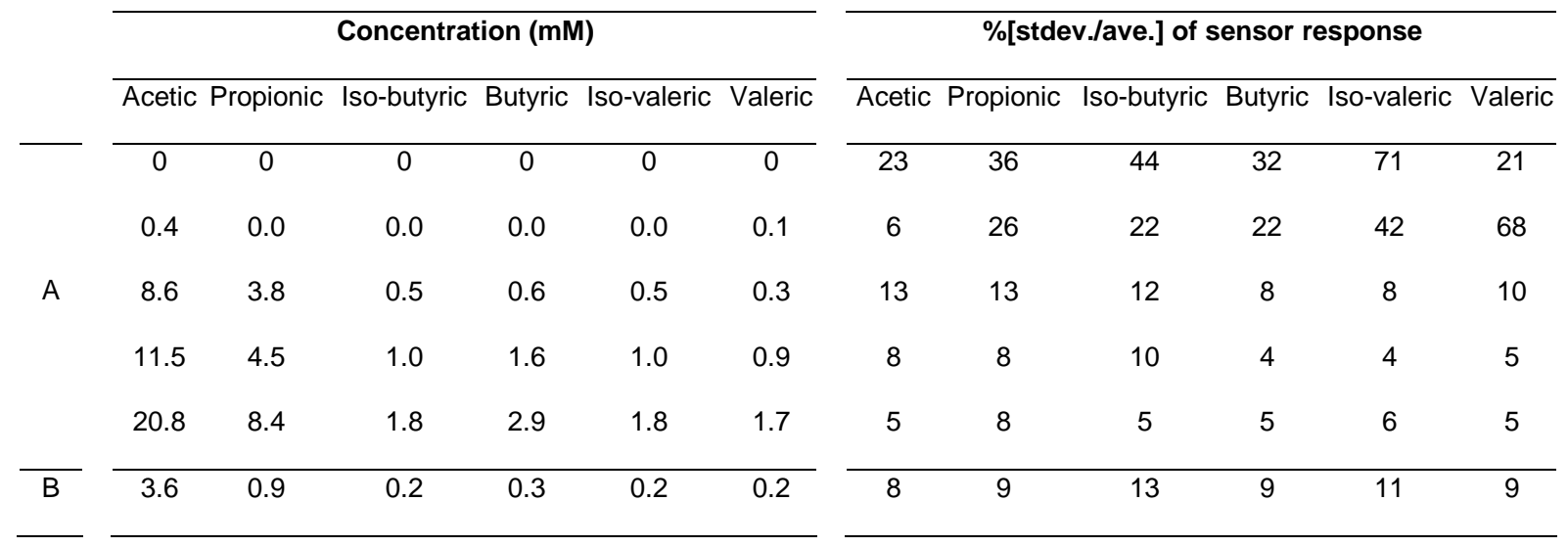




\section{Figures}

Figure 1. Diagram of the sampling system.

Figure 2. Results from optimisation of sampling condition for: acid volume (a), equilibrium temperature (b), salt type (c), salt volume (d) and equilibrium time (e); Symbol: acetic acid ( $\diamond)$, propionic acid $(\square)$, iso-butyric acid $(\triangle)$, butyric acid $(\times)$, iso-valeric acid $(*)$, valeric acid $(\circ)$. Dashed lines indicate optimum.

Figure 3. Effect of bicarbonate alkalinity in the sample

Figure 4. Correlation of the sensor response to the VFA concentration from offline analysis; (a) Acetic acid, (b) Propionic and Butyric acid, (c) Isobutyric, Isovaleric and Valeric acid

Figure 5. Online application with lab-scale CSTR reactor; "o" is the VFA concentration from offline analysis and the line is the VFA from online measurement. 
Biotechnology and Bioengineering, 96(4):712-721.

\section{Figure 1.}

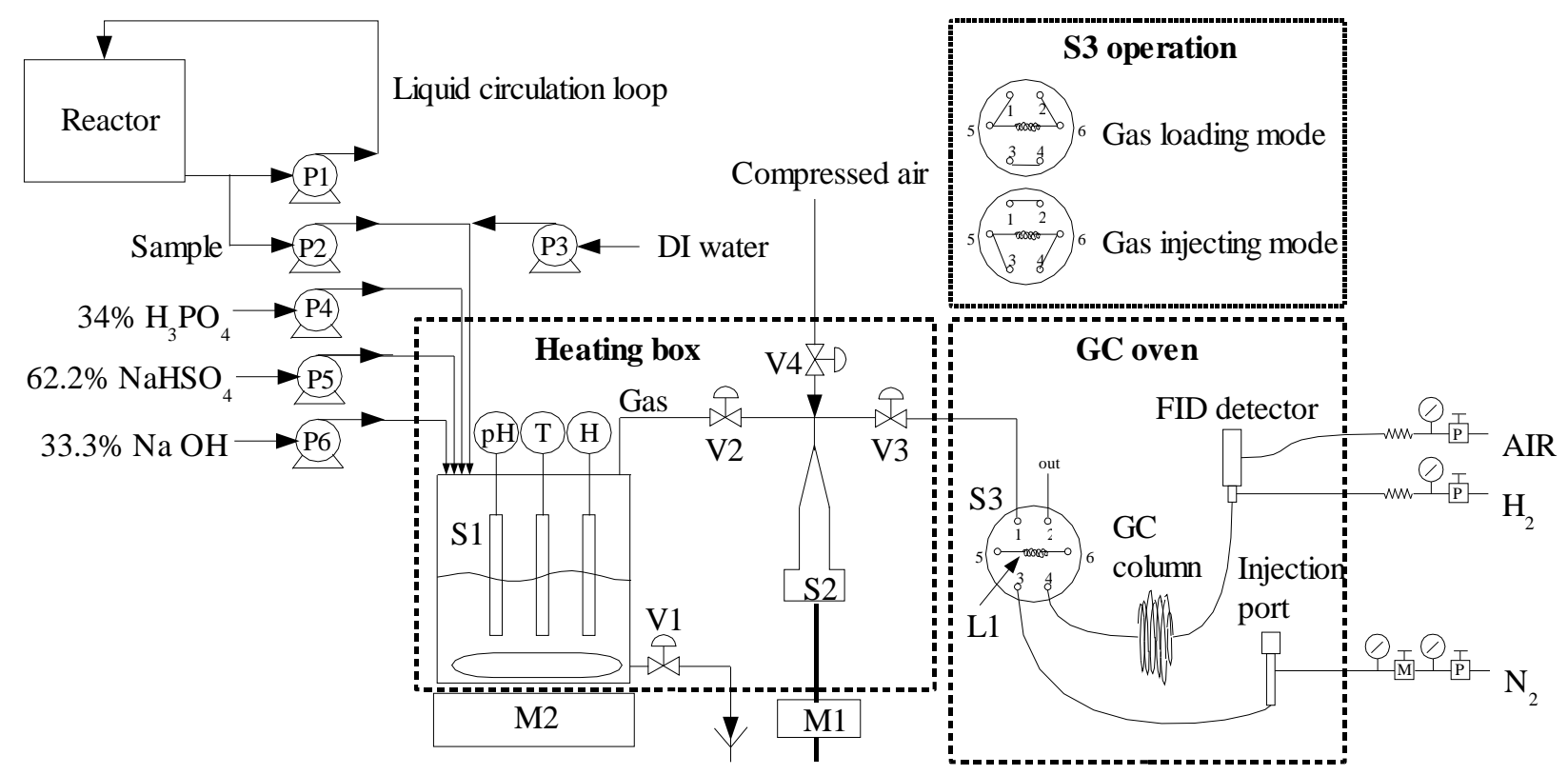


Biotechnology and Bioengineering, 96(4):712-721.

\section{Figure 2.}
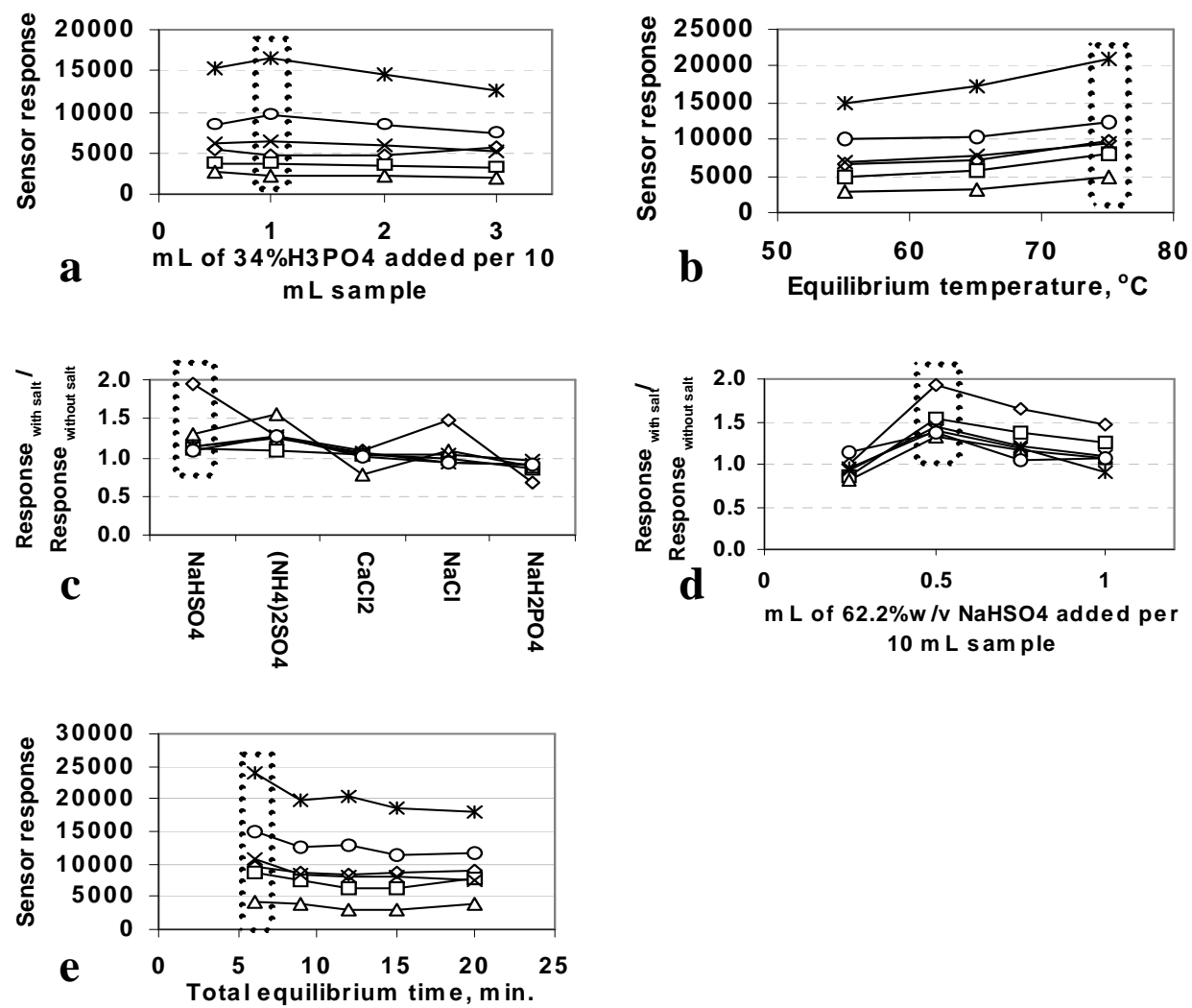
Biotechnology and Bioengineering, 96(4):712-721.

\section{Figure 3.}

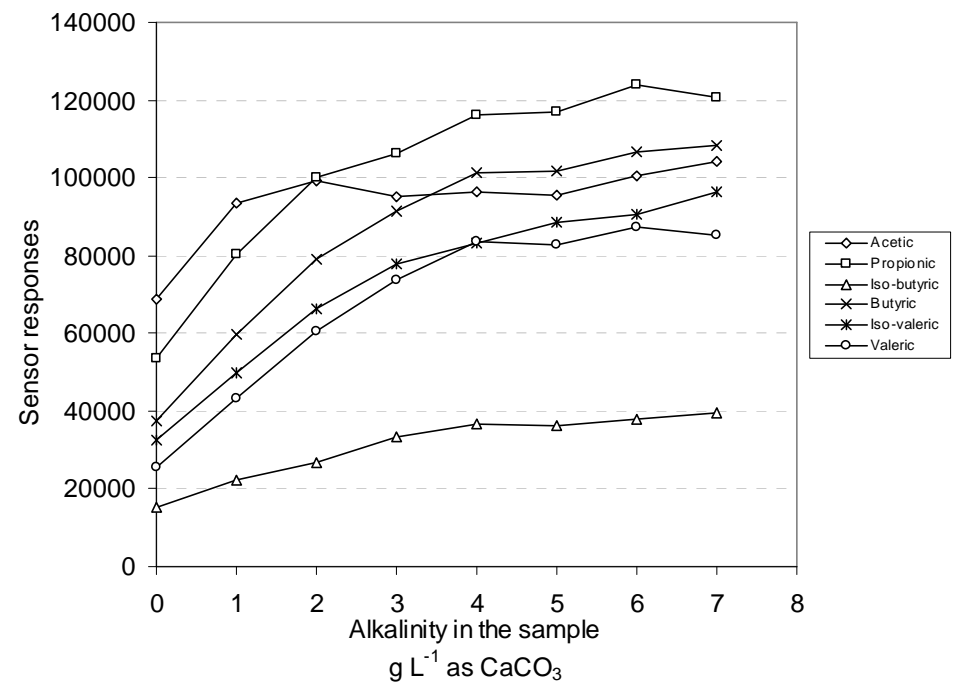


Biotechnology and Bioengineering, 96(4):712-721.

\section{Figure 4.}
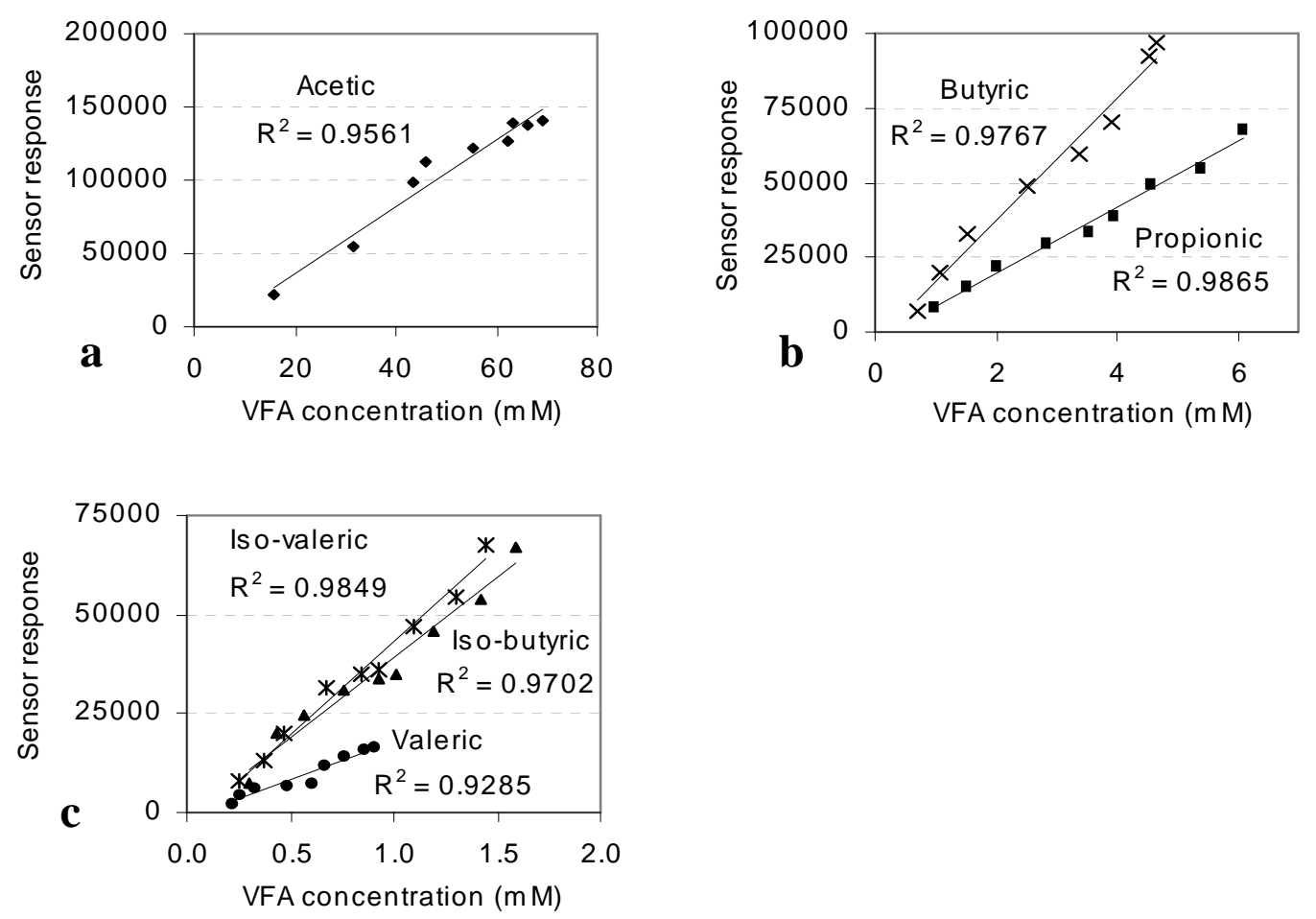
Biotechnology and Bioengineering, 96(4):712-721.

\section{Figure 5.}
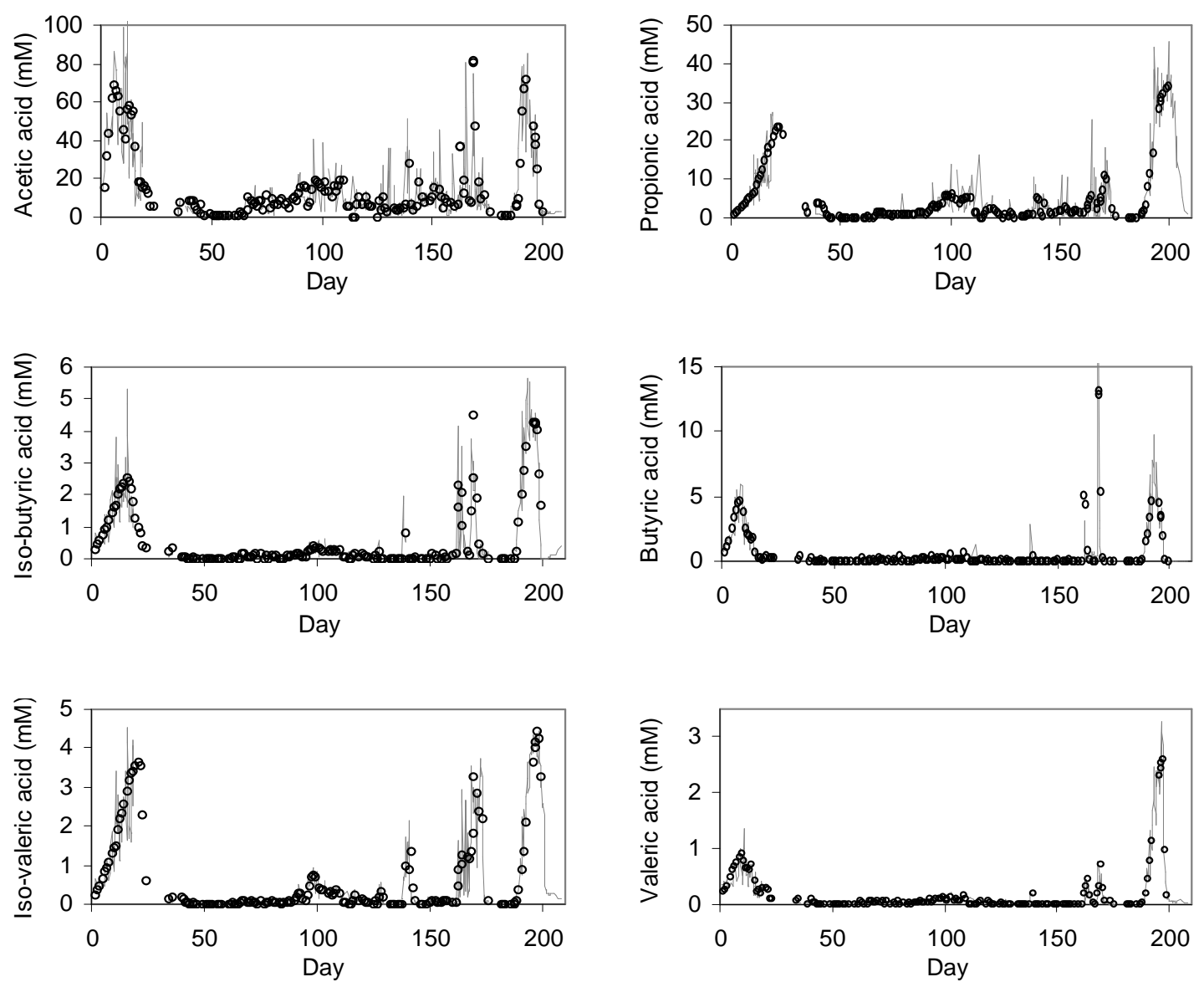